\title{
Impact of nano-sized cerium oxide on physico-mechanical characteristics and thermal properties of the bacterial cellulose films
}

\author{
I. V. Gofman ${ }^{1}$, A. L. Nikolaeva ${ }^{1}$, A. K. Khripunov ${ }^{1}$, A. V. Yakimansky ${ }^{1,2}$, E. M. Ivan'kova ${ }^{1}$, \\ D. P. Romanov ${ }^{3}$, O. S. Ivanova ${ }^{4}$, M. A. Teplonogova ${ }^{4}$, V. K. Ivanov ${ }^{4}$ \\ ${ }^{1}$ Institute of Macromolecular Compounds, Russian Academy of Sciences, 199004, Bolshoi prospect 31, \\ Saint Petersburg, Russia \\ ${ }^{2}$ Saint Petersburg State University, Institute of Chemistry, 198504, Universitetskii prospect 26, \\ Peterhof, Saint Petersburg, Russia \\ ${ }^{3}$ Institute of Silicate Chemistry, Russian Academy of Sciences, 199034, Adm. Makarova emb., 2, \\ Saint Petersburg, Russia \\ ${ }^{4}$ Kurnakov Institute of General and Inorganic Chemistry, Russian Academy of Sciences, 119991, \\ Leninsky prospect 31, Moscow, Russia \\ gofman@imc.macro.ru, alexandra.l.nikolaeva@gmail.com,diadora3@mail.ru, yakimansky@yahoo.com, \\ ivelen@mail.ru,dprom@mail.ru, runetta05@mail.ru, m.teplonogova@gmail.com, van@igic.ras.ru
}

DOI 10.17586/2220-8054-2018-9-6-754-762

\begin{abstract}
A set of nanocomposite film materials based on bacterial cellulose containing nanoparticles of cerium dioxide was prepared. An investigation into the structural and morphological characteristics of the films has been performed, their thermal, mechanical and tribological properties were determined. A protocol of the nanocomposite materials formation used in the work was shown to provide a homogeneous distribution of ceria nanoparticles in the matrix polymer volume in addition to the presence of certain amount of broadly size-dispersed cerium oxide aggregates in the bulk film. The increase of nanoparticles concentration in the composite provokes a progressive growth of the Young's modulus and strength of the film material. Introduction of nanoparticles into the polymer causes the stabilization of sliding friction processes in the tribocontact with steel as well as the decrease of intensity in the wear rate of the film. An increase of the nanoparticles concentration results in a decrease of the material thermal stability.
\end{abstract}

Keywords: polymer-inorganic nanocomposites, bacterial cellulose, ceria, electron microscopy, mechanical properties, thermal stability, tribologic properties.

Received: 5 December 2018

Revised: 8 December 2018

\section{Introduction}

In recent years, so-called natural or "green" polymeric materials, especially cellulose and its derivatives, have attracted much attention from researchers [1]. Materials based on bacterial cellulose (BC) are of special interest [2]. These materials are the products of life activity of Acetobacter bacteria in the nutrient solutions. This type of cellulose is a material of high purity with an enhanced complex of properties [3-6] against those of cellulose of other types.

Interesting prospects are associated with processing of different $\mathrm{BC}$-based compositions filled with inorganic and organic components [7-10], in particular, with various nanoparticles. This approach is widely used for obtaining new materials based on a variety of polymers.

At present, nanoscale fillers are commonly used for modification of the properties of polymeric materials. Oxide nanoparticles are among the most promising. A number of properties of matrix polymer materials can be substantially improved by the introduction of these nanoparticles, namely, the mechanical characteristics, electrical and transport properties, etc. [11-14]. Using metal oxide nanoparticles as an active filler of BC, one can obtain a deep variation the complex of the cellulosic material properties.

One promising group of oxide nanofillers, which draws attention of researchers, is ceria nanoparticles. By using them, one can obtain polymer-based composite materials demonstrating the effect of screening of electromagnetic irradiation, possessing catalytic activity, new materials with modified acoustic characteristics, and bioactive materials [15-20]. Of especial interest are ceria-containing nanocomposites based on BC, particularly as the materials for biomedical applications. In the context of interesting potential possibilities of practical application of such materials, it is sensible to comprehensively characterize them, both per se and in juxtaposition with their unmodified polymer matrices. 
In the present communication, we present and analyze systematic information on the effect of cerium dioxide nanoparticles on the complex of properties of the film materials based on BC.

\section{Experimental}

BC or so-called Acetobacter xylinum was grown by using VKM- 880 strain in aqueous solutions containing 2 wt. $\%$ of glucose, $0.3 \mathrm{wt} . \%$ of yeast extract and $2 \mathrm{wt} . \%$ of ethanol at $30{ }^{\circ} \mathrm{C}$ in cylindrical glass vessels for $14-21$ days as described in detail in [21]. The as-prepared BC samples being gel-like pellicles with up to $25 \mathrm{~mm}$ thickness were partially dehydrated by pressing on a hand press, $\mathrm{BC}$ content in the pressed $\mathrm{BC}$ being about 14 wt. $\%$.

To obtain both the $\mathrm{BC}$ and nanocomposite films, the pressed $\mathrm{BC}$ was disintegrated in a high-speed blender (15000 rpm, $15 \mathrm{~min}$ ) in aqueous media ( $300 \mathrm{ml}$ of water per $1 \mathrm{~g}$ of dry BC). In the case of nanocomposites, definite amounts of aqueous dispersion of cerium dioxide nanoparticles (ceria concentration $-1.5 \mathrm{wt} . \%$ ) were poured into the preliminary prepared $\mathrm{BC}$ aqueous suspension, and then, the mixtures obtained were homogenized in a blender (15000 rpm, $1 \mathrm{~min}$ ). In both cases, layers of equal thickness of resulting homogeneous suspensions were formed on a glass substrates and dried to constant weight at $160{ }^{\circ} \mathrm{C}$. The final concentrations of $\mathrm{CeO}_{2}$ nanoparticles in the samples were $0,1,3,5$, and $10 \mathrm{wt}$ \%. Cerium dioxide nanoparticles with sizes $\sim 3.5 \mathrm{~nm}$ used in our experiments were synthesized by hydrothermal method [22].

XDR analysis of $\mathrm{BC}$ and composite films was carried out by X-ray diffractometer DRON-3M (CuK $\alpha$ irradiation). The registration of X-ray beam diffraction was performed according to the Bragg-Brentano scheme [23].

SEM micrographs of films' surfaces were obtained by scanning electron microscope SUPRA-55VP (Carl Zeiss, Germany) using a secondary electron detector as well as a detector of back-scattered electrons. The samples were fixed with special glue on the microscope holders and sputtered by thin layer of platinum. Maps of the elements distribution were collected using a detector of energy dispersive X-ray analysis X-max $80 \mathrm{~mm}^{2}$ (Oxford Instruments, United Kingdom).

Thermogravimetric analysis (TGA) of BC and composite samples was performed using a DTG-60 thermal analyser (Shimadzu, Japan). Specimens $(\sim 5 \mathrm{mg})$ were heated in air up to $600{ }^{\circ} \mathrm{C}$ with the rate of $5{ }^{\circ} \mathrm{C} / \mathrm{min}$. The TGA curves obtained were used to determine the thermal stability indices of the materials under study, $\tau_{5}$ and $\tau_{10}$ (the temperature values at which a polymer or a composite loses $5 \%$ and $10 \%$ of its initial weight, respectively, due to the thermal destruction processes).

The mechanical tests of the films under investigation were carried out in the uniaxial extension mode at room temperature using an AG-100kNX Plus universal mechanical test system (Shimadzu, Japan). Strip-like samples $2 \times 30 \mathrm{~mm}$ were stretched at a rate of $10 \mathrm{~mm} / \mathrm{min}$, according to ASTM D638 requirements. The Young's modulus $E$, the break stress $\sigma_{b}$ and the ultimate deformation $\varepsilon_{b}$ were determined.

Tribological characteristics of the films (friction coefficients and wear rates) were studied by an AG-100kNX Plus universal mechanical test system (Shimadzu, Japan) with a tribological tests accessory [24] in the dry friction mode at room temperature. The speed of linear shuttle motion of the counterbodies against the polymer surfaces was as high as $1000 \mathrm{~mm} / \mathrm{min}$.

\section{Results and discussion}

First, it should be noted, that the aforementioned technique provides a means for obtaining dense homogeneous films. XRD analysis of their compositions has demonstrated the presence of $\mathrm{CeO}_{2}$ inclusions (Fig. 1): X-ray diffraction patterns of the composite films contain the reflexes corresponding to $\mathrm{BC}$ and those at $2 \Theta=28.5,33.7$ and 47.4 deg., corresponding to cubic phase of crystalline $\mathrm{CeO}_{2}$. The intensity of these reflexes increases along with the increase of the nanoparticles concentration in the cellulose matrix. A considerable broadening of the reflexes in comparison with those in the diffractogram of pure cerium dioxide (Fig. 1, curve 4) points out the very small dimensions of domains of the composite material in which the diffraction takes place.

The microscopic images of the studied samples are presented in Fig. 2. Fig. 2(a) presents the nanoparticles of $\mathrm{CeO}_{2}$. One can see that in a dried state this material consists of broad aggregates of individual ceria nanoparticles. This tendency to the agglomeration processes is inherent to this nanofiller. So some special cares were provided during the formation of the nanocomposite films to insure the distribution of ceria in the $\mathrm{BC}$ volume as uniform as possible (see the "Materials and methods' section).

A sample of pure bacterial cellulose (Fig. 1(b)) consists of fibrils with a diameter of $30 \mathrm{~nm}$. The samples filled with $\mathrm{CeO}_{2}$ nanoparticles (Fig.1 c-e) were studied using a back-scattered electron detector capable of detecting the so-called Z-contrast having an atomic-number $(Z)$ sensitive nature, i.e. the higher the atomic number of the element, the brighter it appears in the microscopic image. In this particular case, $\mathrm{CeO}_{2}$ particles should look 


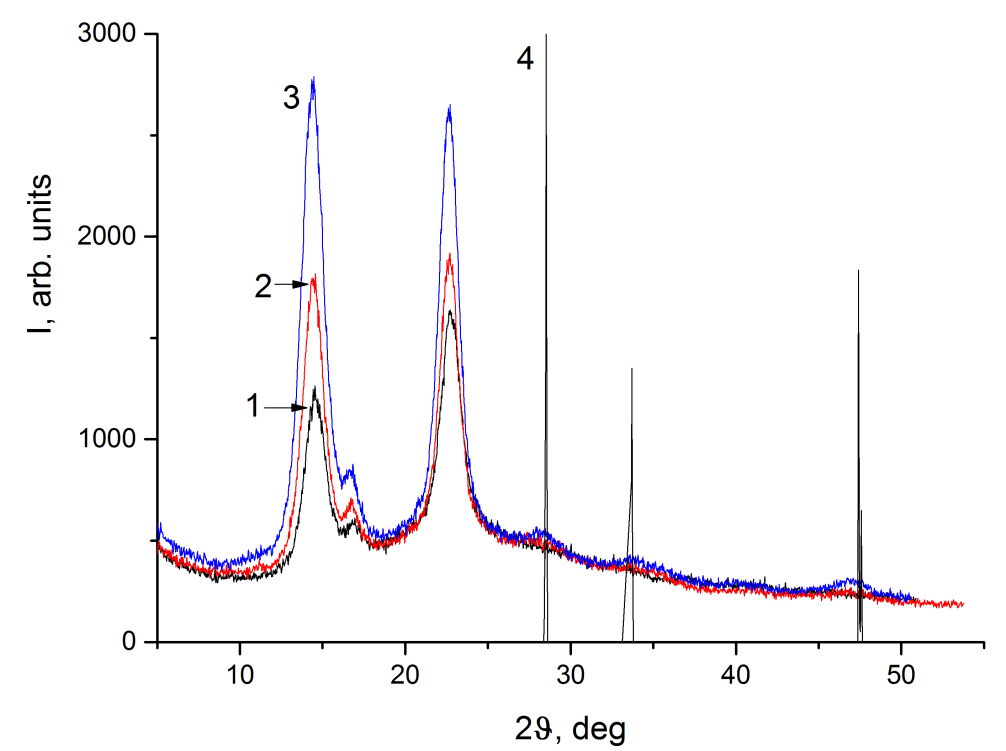

FIG. 1. Diffractograms of the films: BC (1), nanocomposites with 3 and 10 wt. \%, (2 and 3, respectively); X-ray diffraction pattern of crystalline cerium dioxide, cubic phase (4)

most bright. This figure clearly shows that $\mathrm{CeO}_{2}$ nanoparticles are not well-dispersed in the matrix of bacterial cellulose. $\mathrm{CeO}_{2}$ aggregates of various sizes are observed. In this case, we can conclude that the higher the content of nanofiller particles in the composite material, the larger the sizes of the detected $\mathrm{CeO}_{2}$ aggregates.

The following figure (Fig. 3) shows the results of energy dispersive X-ray analysis (EDX) of the nanocomposite films tested (Fig. 3(c, e, g)). This research method allows one to collect maps of the elements distribution. All the EDX data obtained clearly revealed the presence of cerium (indicated in yellow) in the test samples on the same parts of the samples, which are also shown in SEM micrographs on the left side (Fig. 3(b, d, f)). Moreover, its content corresponds to the calculated one.

The obtained cerium distribution maps for different samples confirm the SEM results discussed above, i.e. the higher the content of introduced $\mathrm{CeO}_{2}$ nanoparticles, the higher the probability of detecting large agglomerates containing cerium. At the same time, there is a certain proportion of nanoparticles that is uniformly distributed in the samples.

Cerium dioxide is known to act as a catalyst in the destructive processes of organic compounds and to significantly affect the redox processes in the latter [25]. It was interesting to verify the effect of $\mathrm{CeO}_{2}$ nanofiller on the thermal destruction of $\mathrm{BC}$ in the air atmosphere. The curves of $\mathrm{BC}$ and $\mathrm{BC}-\mathrm{CeO}_{2}$ nanocomposite films weight losses $v s$. temperature in the said conditions are shown in Fig. 4. The TGA curves obtained are typical for cellulose thermal destruction. The first region of weight losses $(2-2.5 \mathrm{wt}$. \%) observed at temperatures up to $100{ }^{\circ} \mathrm{C}$ is related to evaporation of water and low-molecular compounds, which are adsorbed on the cellulose surface. At temperatures $190-350{ }^{\circ} \mathrm{C}$ (depending on $\mathrm{CeO}_{2}$ content) all of the samples undergo thermo-oxidative decomposition. Finally, at the terminal phase (at the highest temperatures) the carbonaceous residue interacts with atmospheric oxygen bringing to formation of $\mathrm{CO}$ and $\mathrm{CO}_{2}$. As a result, an organic part of the sample was completely destroyed in the oxidative atmosphere (coke residue weigh is 0 ). The analysis of TGA curves reveals that the doping of $\mathrm{BC}$ matrix with $\mathrm{CeO}_{2}$ nanoparticles as well as increasing of their content leads to a gradual temperature decrease of all of the aforementioned processes. This, obviously, confirms a noticeable catalytic activity of nano-sized cerium dioxide in the thermal oxidative destruction of cellulose. Indeed, embedment of these nanoparticles in concentrations 5 and $10 \mathrm{wt} . \%$ results in a decrease in thermal stability index, $\tau_{5}$, by 29 and 45 degrees, respectively (See Table 1).

The results of mechanical tests of the films (Table 2) demonstrate an increase in stiffness of matrix polymer upon introduction of $\mathrm{CeO}_{2}$ nanoparticles therein. Due to the hyperbranched system of hydrogen bonds, $\mathrm{BC}$ is a quite rigid, high-modulus polymer material [26]. In our study, we have observed a gradual augment of Young's moduli of the films as $\mathrm{CeO}_{2}$ content was increased (Table 2). In fact, Young's moduli of the nanocomposite films with 5 and 10 wt. $\%$ of cerium dioxide are increased 1.25 and 1.63 fold, relative to that of a pristine BC film. A simultaneous increase of material tensile strength was also registered. On the other hand the composite film with even the highest concentration of $\mathrm{CeO}_{2}$ nanoparticles exhibits no deterioration of elongation at break value. The 


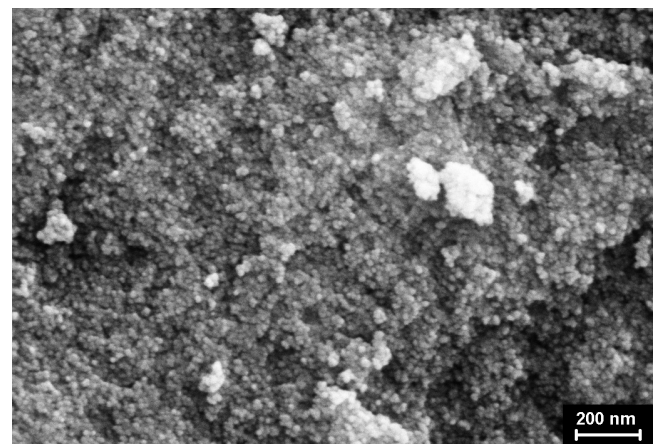

(a)

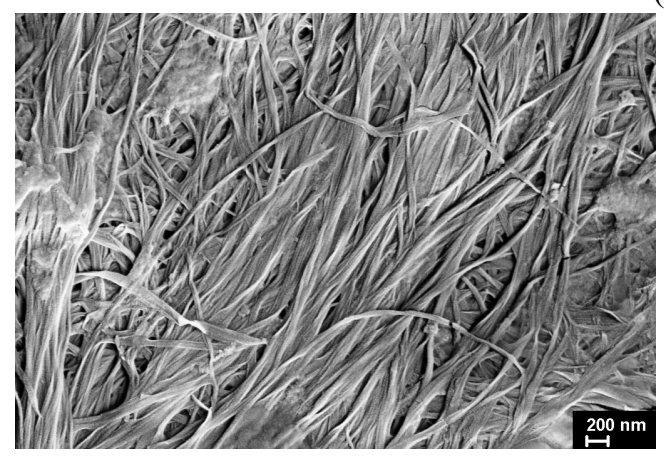

(b)

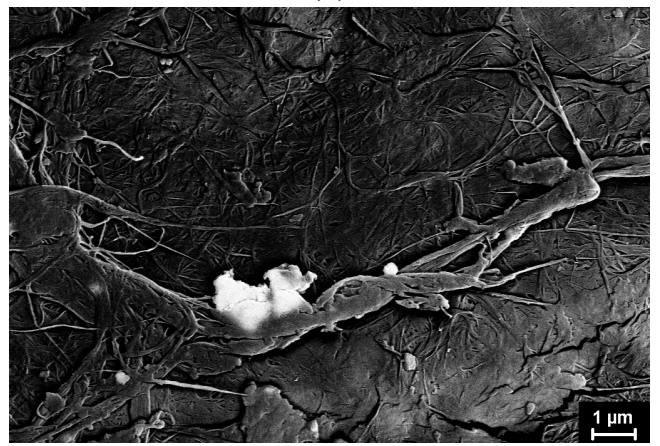

(d)

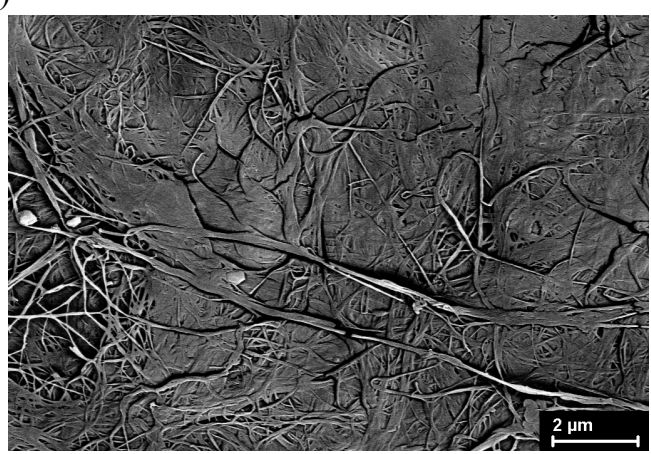

(c)

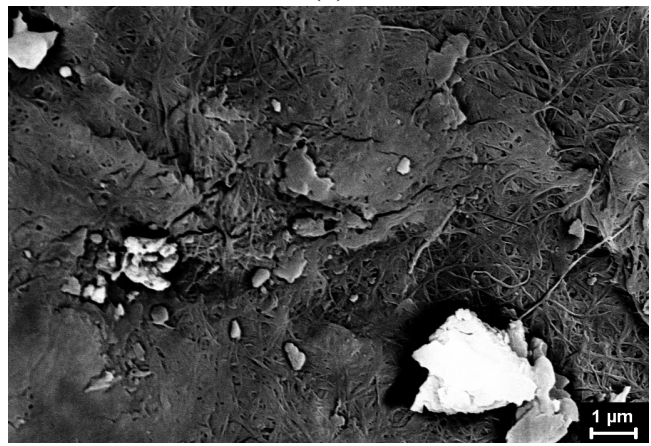

(e)

FIG. 2. SEM micrographs of the investigated samples: (a) - $\mathrm{CeO}_{2}$ nanoparticles; (b) - pure $\mathrm{BC}$; (c-d) - BC-ceria nanocomposite films containing 3, 5, and $10 \mathrm{wt} \% \mathrm{CeO}_{2}$; respectively

TABLE 1. Indices of thermal stability of $\mathrm{BC}$ and $\mathrm{BC}$-ceria nanocomposite films

\begin{tabular}{|c|c|c|c|}
\hline Sample & $\tau_{1},{ }^{\circ} \mathrm{C}$ & $\tau_{5},{ }^{\circ} \mathrm{C}$ & $\tau_{10},{ }^{\circ} \mathrm{C}$ \\
\hline \hline $\mathrm{BC}$ & 258 & 288 & 302 \\
\hline Composite, 1 wt.\% of $\mathrm{CeO}_{2}$ & 241 & 284 & 299 \\
\hline Composite, 3 wt.\% of $\mathrm{CeO}_{2}$ & 202 & 272 & 290 \\
\hline Composite, 5 wt.\% of $\mathrm{CeO}_{2}$ & 194 & 259 & 282 \\
\hline Composite, 10 wt. $\%$ of $\mathrm{CeO}_{2}$ & 181 & 243 & 274 \\
\hline
\end{tabular}




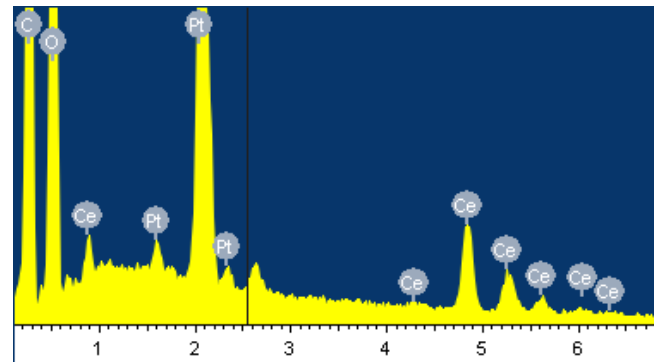

(a)

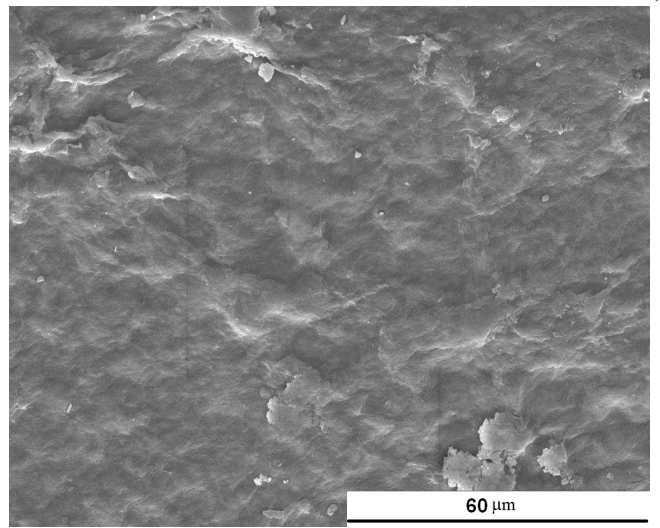

(b)

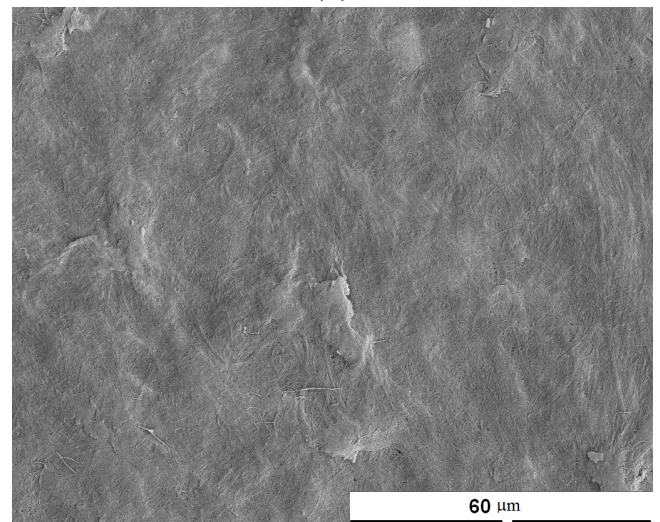

(d)

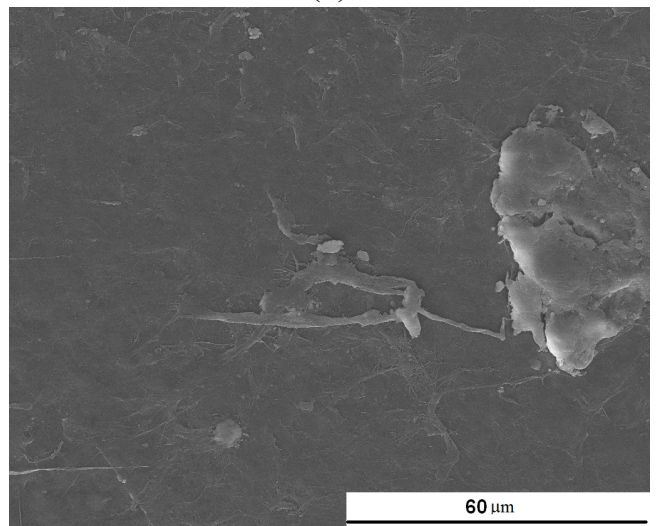

(f)

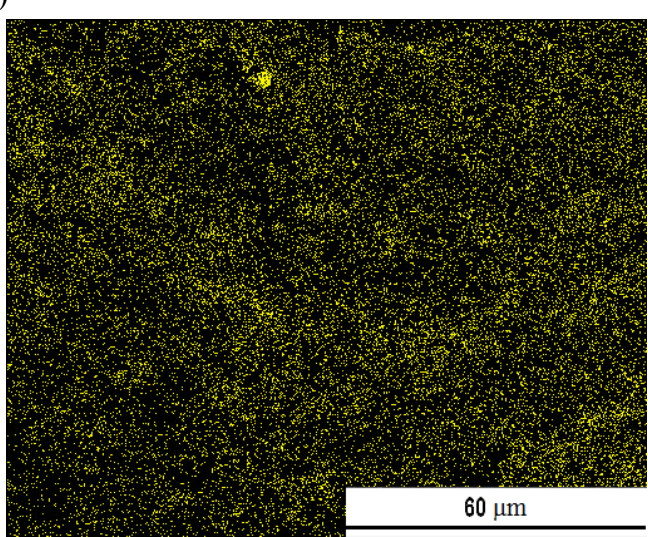

(c)

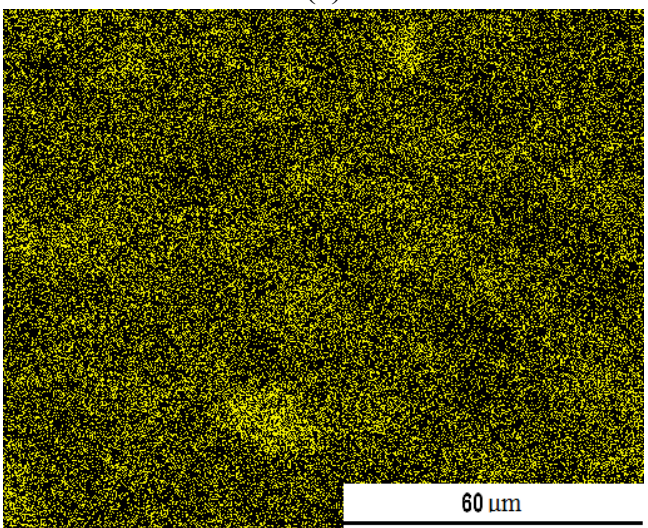

(e)

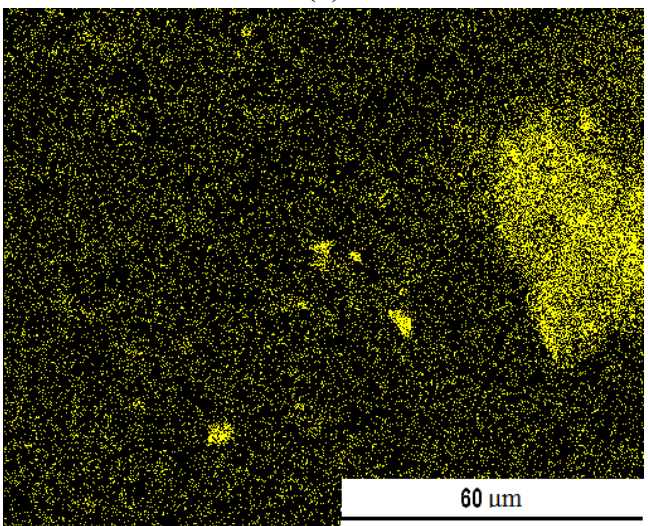

(g)

FIG. 3. (a) - An example of EXD spectra obtained for investigated samples. SEM micrographs (left side) and EXD maps of cerium distribution (right side) of the nanocomposite samples containing: (b, c) - 3 wt. $\% \mathrm{CeO}_{2}$; (d, e) - 5 wt. $\% \mathrm{CeO}_{2}$; (f, g) -10 wt. $\% \mathrm{CeO}_{2}$ 


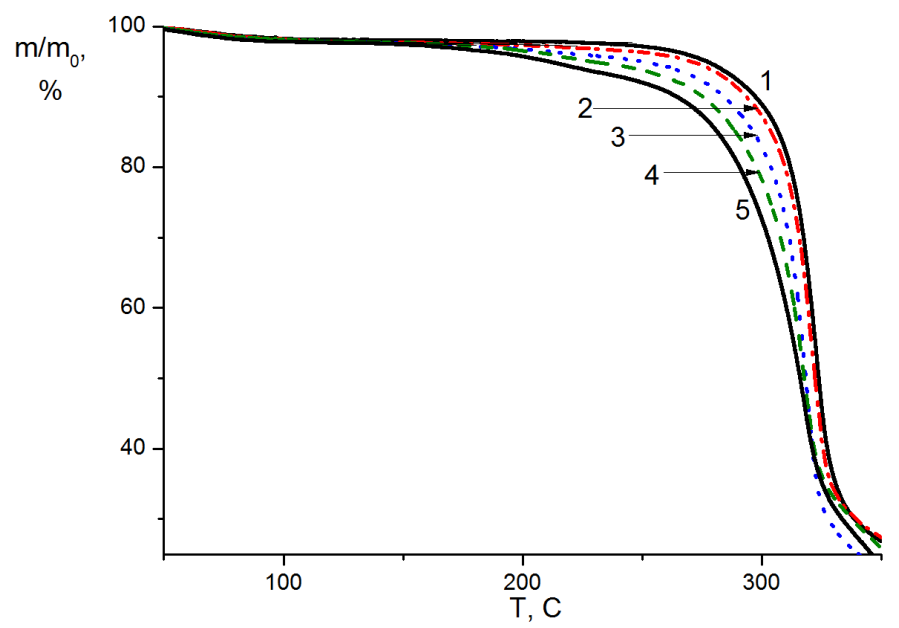

FIG. 4. TGA curves of (1) $\mathrm{BC}$ and (2-5) $\mathrm{BC}$-ceria nanocomposite films. $\mathrm{CeO}_{2}$ concentrations in the materials are $(2)-1 \%,(3)-3 \%,(4)-5 \%$ and $(5)-10 \%$

TABLE 2. Mechanical characteristics of BC film and BC-ceria nanocomposite ones

\begin{tabular}{|c|c|c|c|c|}
\hline No. & Sample & $E, \mathrm{GPa}$ & $\sigma_{b}, \mathrm{MPa}$ & $\varepsilon_{b}, \%$ \\
\hline \hline 0 & $\mathrm{BC}$ & $6.41 \pm 0.56$ & $96 \pm 6$ & $3.9 \pm 0.4$ \\
\hline 1 & Composite, 1 wt.\% of $\mathrm{CeO}_{2}$ & $6.46 \pm 0.42$ & $94 \pm 3$ & $4.0 \pm 0.5$ \\
\hline 2 & Composite, 3 wt.\% of $\mathrm{CeO}_{2}$ & $6.75 \pm 0.43$ & $98 \pm 7$ & $3.9 \pm 0.4$ \\
\hline 3 & Composite, 5 wt.\% of $\mathrm{CeO}_{2}$ & $8.02 \pm 0.56$ & $108 \pm 5$ & $4.1 \pm 0.5$ \\
\hline 4 & Composite, 10 wt.\% of $\mathrm{CeO}_{2}$ & $10.45 \pm 0.36$ & $132 \pm 6$ & $4.4 \pm 0.5$ \\
\hline
\end{tabular}

latter fact is quite interesting given that a wide range of polymers show the opposite behavior when doped with nanoparticles [27].

The significant increase in the material stiffness that we recorded, caused by the introduction of cerium dioxide into the polymer matrix, can hardly be explained by the well-known physical effect of reinforcement observed when nanoparticles such as carbon nanotubes, nanofibers, and graphene are introduced into different polymeric materials [27]. Indeed, unlike all the said and a number of other nanoscale fillers, characterized by a pronounced geometrical anisotropy with high aspect ratio values, cerium dioxide nanoparticles have a spherical or quasi-spherical shape, that is, they are characterized by an aspect ratio close to 1 . With the introduction of fillers of such types with poor aspect ratios into the bulk of the polymer material, reinforcement effects can be expected at their much higher concentrations than those implemented in the composites we studied [28].

It should be assumed that the introduction of cerium dioxide in $\mathrm{BC}$ leads to profound changes in the structure of the intermolecular bonds in this material, to a steady increase in their number (as the concentration of nanoparticles increases). This effect can explain the changes in the stiffness and strength of the material, observed when cerium dioxide is introduced into the BC.

Such behavior of nanocomposite material can find room in a number of practical uses, e.g., for the tailoring of various materials for biomedical applications, primarily for materials for surgery, to which the presence of cerium oxide in $\mathrm{BC}$ will procure bactericidal properties and enhance healing of lesions [29,30].

Another mode of work of polymeric materials under the long-term action of mechanical stresses, which is interesting and important from the viewpoint of the possible practical use of the materials, is their behavior in the friction couples, for example in the couples with metals. Lately a potential possibility of the polymer materials to be used as components of the friction units became the subject of close interest of the researchers. Albeit, in general, the nanosized fillers can improve the tribologic properties of different polymer materials [31,32], ceria 
particles are known to be widely used as abrasive materials [33,34]. In line with this circumstance we have tackled clarifying the effect of the ceria nanoparticles on the tribologic behavior of the $\mathrm{BC}$ films in the friction couple with the stainless steel.

At the first stage of these experiments, we have determined the $k$ value of the matrix $\mathrm{BC}$ in the couple with steel (Fig. 5). The results obtained are typical for cellulose materials $-\sim 0.36-0.42$ depending upon the normal load $F_{z}$.

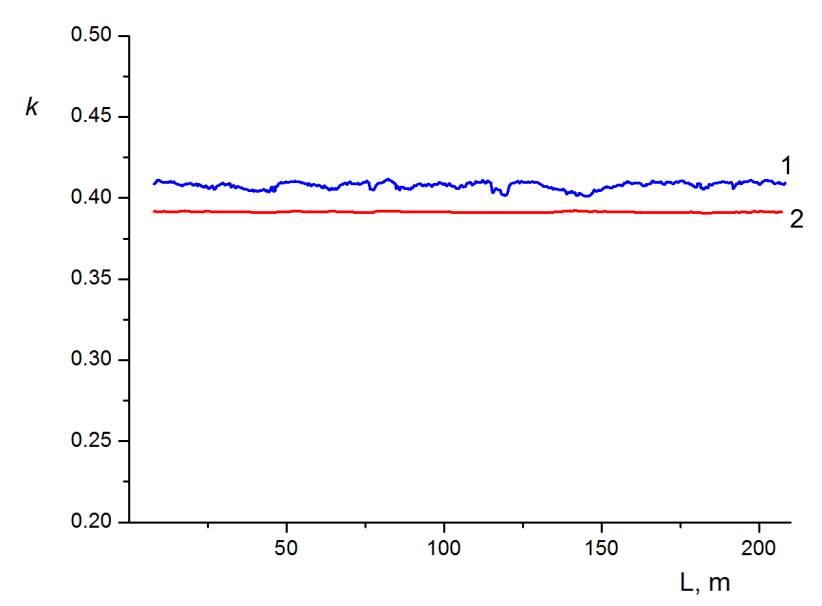

FIG. 5. Friction curves of (1) BC/steel and (2) BC-ceria/steel couples. The ceria concentration is 3 wt. \%, the mean normal pressure $-10 \mathrm{MPa}$

The experiments carried out at the next step of the investigation (Fig. 5) have shown that introduction of ceria nanoparticles into the polymer at a concentration of 3 wt. \% does not provoke any significant change of the polymer/steel friction coefficient: the $k$ value of the composite film is 0.391 , while that of the unfilled polymer film -0.407 (at the mean value of normal stress $10 \mathrm{MPa}$ ). However, another positive effect of the ceria nanoparticles introduction was observed: the friction process becomes more stable against that in the $\mathrm{BC} / \mathrm{steel}$ friction couple (Fig. 5), practically no noticeable changes or fluctuations, no wobbles in the $k$ value were registered during the friction experiment.

A more pronounced positive effect of the ceria introduction into the polymer, registered in the tribologic tests, is a decrease of the wear rate of the nanocomposite material as compared to that of the unfilled $\mathrm{BC}$ film. The mass wear rate $\mathrm{W}$ was determined as:

$$
W=\frac{\Delta m}{L \times \rho \times F_{z}},
$$

where $\Delta m$ denotes the mass loss during the test, $L$ is the running distance during the test, $\rho$ - the density of the polymer tested, and $F_{z}$ - the normal contact load.

The $W$ value of unfilled $\mathrm{BC}$ film was found to be as high as $4 \times 10^{-3} \mathrm{~mm}^{3} / \mathrm{Nm}$ (the average roughness Ra of the steel surface was about $1.0 \mu \mathrm{m}$ ). The BC-ceria nanocomposite film is characterized by a substantial depression of the wear rate down to $7 \times 10^{-4} \mathrm{~mm}^{3} / \mathrm{Nm}$. This positive effect can be attributed to stabilization of the friction process provided by the nanoparticles inserted in the BC volume (Fig. 5).

\section{Conclusions}

The protocol of film formation from mixtures of aqueous suspensions of disintegrated $\mathrm{BC}$ and ceria nanoparticles elaborated in the present work provides an algorithm of preparation of the stiff and non-brittle nanocomposite films. During the film preparation a partial aggregation of ceria takes place, the phenomenon presumably occurring at the stage of the film drying. In accordance with the data obtained in the XRD and SEM examinations of the films, a substantial portion of the ceria nanoparticles is distributed uniformly in the volume of the material. This situation takes place up to the maximal concentration of ceria used in our work: $10 \mathrm{wt}$. \%.

The mechanical tests of the films demonstrate the progressive increase of both the Young's modulus and the ultimate stress values along with the increase of the nanofiller's concentration in the material without any depression of the ultimate deformation. These facts indicate possible formation of certain system of interactions between $\mathrm{BC}$ macrochains and ceria nanoparticles in the nanocomposite materials obtained. 
The tribologic tests of both $\mathrm{BC}$ and composite films in the friction couples with steel have given evidence for the substantial stabilization of the friction process caused by introduction of ceria into BC bulk along with the significant decrease of the mass wear rate of the material.

A substantial successive decrease of the thermal stability of the films provoked by the increase in the ceria concentration was registered in the thermogravimetric tests in air, the fact testifying catalytic action of ceria during thermo-oxidative destruction of BC. However, this specific feature of the nanocomposite materials studied does not appear to be a hindrance for the practical use of these materials in the biomedical applications.

\section{Acknowledgements}

The work was financially supported by the Russian Science Foundation (grant No. 18-13-00305).

\section{References}

[1] Cellulose Chemistry and Properties: Fibers, Nanocelluloses and Advanced Materials. Ed. O. J. Rojas. Springer International Publishing, Switzerland, 2016.

[2] Esa F., Tasirin S.M., Rahman N.A. Overview of Bacterial Cellulose Production and Application. Agriculture and Agricultural Science Procedia, 2014, 2, P. 113-119.

[3] Mitrofanov R.Y., Budaeva V.V., Sakovich G.V. Preparation and Properties of Bacterial Cellulose Gel Films. Chemistry for Sustainable Development, 2010, 18, P. 503-508.

[4] Gromovykh T.I., Sadykova V.S., et al. Bacterial cellulose synthesized by Gluconacetobacter hansenii for medical applications. Applied Biochemistry and Microbiology, 2017, 53, P. 60-67.

[5] Backdahl H., Helenius G., et al. Mechanical properties of bacterial cellulose and interactions with smooth muscle cells. Biomaterials, 2006, 27, P. 2141-2149.

[6] Feng X., Ullah N., et al. Characterization of Bacterial Cellulose by Gluconacetobacter hansenii CGMCC 3917. Journal of Food Science, 2015, 80 (10), E2217-27.

[7] Shah N., Ul-Islam M., Khattak W.A., Park J.K. Overview of bacterial cellulose composites: A multipurpose advanced material. Carbohydrate Polymers, 2013, 98, P. 1585-1598.

[8] Nainggolan H., Gea S., et al. Mechanical and thermal properties of bacterial-cellulose-fibre-reinforced Mater-Bi bionanocomposite. Beilstein J. Nanotechnol., 2013, 4, P. 325-329.

[9] Buyanov A.L., Gofman I.V., et al. Anisotropic swelling and mechanical behavior of composite bacterial cellulose-(polyacrylamide or polyacrylamide-sodium polyacrylate) hydrogels. Journal of the mechanical behaviour of biomedical materials, 2010,3 , P. $102-111$.

[10] Smyslov R.Yu., Ezdakova K.V.,et al. Morphological structure of Gluconacetobacter xylinus cellulose and cellulose-based organic-inorganic composite materials. Journal of Physics: Conference Series, 2017, 848, P. 012017-012028.

[11] Shah P., Pandey K. Advancement in packaging film using microcrystalline cellulose and $\mathrm{TiO}_{2}$. American Journal of Polymer Science and Technology, 2017, 3, P. 97-102.

[12] Bouadjela S., Abdoune F.Z., et al. Effect of titanium dioxide nanoparticles on polymer network formation. Spectroscopy Letters, 2017, 50, P. 522-527.

[13] Tamayo L., Azocar M., et al. Copper-polymer nanocomposites: An excellent and cost-effective biocide for use on antibacterial surfaces. Review. Materials Science and Engineering C, 2016, 69, P. 1391-1409.

[14] Mallakpour S., Darvishzadeh M. Ultrasonic treatment as recent and environmentally friendly route for the synthesis and characterization of polymer nanocomposite having PVA and biosafe BSA modified ZnO nanoparticles. Polymers for Advanced Technologies, 2018, 29, P. 2174-2183.

[15] Lu Z., Mao C., et al. Fabrication of $\mathrm{CeO}_{2}$ nanoparticle-modified silk for UV protection and antibacterial applications. Journal of Colloid and Interface Science, 2014, 435, P. 8-14.

[16] Liu K.-Q., Kuang C.-X., et al. Synthesis, characterization and UV-shielding property of polystyrene-embedded CeO 2 nanoparticles. Optical Materials, 2013, 35, P. 2710-2715.

[17] Mullins D.R. The surface chemistry of cerium oxide. Surface Science Reports, 2015, 70, P. 42-85.

[18] Tiefensee F., Becker-Willinger C., et al. Nanocomposite cerium oxide polymer matching layers with adjustable acoustic impedance between 4 MRayl and 7 MRayl. Ultrasonics, 2010, 50, P. 363-366.

[19] Jia R.-P., Wang C.-F., et al. Preparation, characterization, and properties of $\mathrm{CeO}_{2} /$ thermoplastic polyurethane nanocomposites. Journal of Reinforced Plastics and Composites, 2015, 34, P. 1090-1098.

[20] Shang Z., Lu C., Lu X., Gao L. Studies on syntheses and properties of novel $\mathrm{CeO}_{2} /$ polyimide nanocomposite films from Ce(Phen) 3 complex. Polymer, 2007, 48, P. 4041-4046.

[21] Buyanov A.L., Revel'skaya L.G., Kuznetzov Yu.P., Shestakova A.S. Cellulose-poly(acrylamide or acrylic acid) interpenetrating polymer membranes for the pervaporation of water-ethanol mixtures. J. Appl. Polym. Sci., 1998, 69, P. 761-768.

[22] Ivanov V.K., Polezhaeva O.S., et al. Synthesis and thermal stability of nanocrystalline ceria sols stabilized by citric and polyacrylic acids. Russian Journal of Inorganic Chemistry, 2010, 55 (3), P. 328-332.

[23] Kriegner D., Matej Z., Kuzel R., Holý V. Powder diffraction in Bragg-Brentano geometry with straight linear detectors. J. Appl. Cryst., 2015, 48, P. 613-618.

[24] Gofman I., Larin S., Liulin S., Falkovich S. The device for the determination of coefficient of sliding friction. Patent of Russian Federation No. 150882, Published 10.03.2015. Inventions. Useful models. 2015. No 7.

[25] Mullins D.R. The surface chemistry of cerium oxide. Surface Science Reports, 2015, 70, P. $42-85$.

[26] Kannam S.K., Oehme D.P., et al. Hydrogen bonds and twist in cellulose microfibrils. Carbohydrate Polymers, 2017,175 , P. $433-439$.

[27] Valenkov A.M., Gofman I.V., et al. Polymeric Composite Systems Modifi ed with Allotropic Forms of Carbon (Review). Russian Journal of Applied Chemistry, 2011, 84 (5), P. 735-750. 
[28] Garboczi E.J., Snyder K.A., Douglas J.F., Thorpe M.F. Geometrical percolation threshold of overlapping ellipsoids. Phys. Review. E, 1995, 52 (1), P. 819-828.

[29] Rajeshkumar S., Naik P. Synthesis and biomedical applications of Cerium oxide nanoparticles - A Review. Biotechnology Reports, 2018, 17, P. 1-5.

[30] Popov A.L., Ermakov A.M., et al. Biosafety and effect of nanoparticles of $\mathrm{CeO}_{2}$ on metabolic and proliferative activity of human mesenchymal stem cells In Vitro. Int. J. Nanomech. Sci. Tech., 2016, 7, P. 165-175.

[31] Aly A., Zeidan E., et al. Friction and Wear of Polymer Composites Filled by Nano-Particles: A Review. World Journal of Nano Science and Engineering, 2012, 2, P. 32-39.

[32] Chamnipan R., Chutima S., Uthaisangsuk V. Processing and characterization of nano filler containing friction materials. Materials Today: Proceedings, 2018, 5, P. 9467-9475.

[33] Shin C., Choi J., et al. Trace metals optimization in ceria abrasive for material removal rate enhancement during ILD CMP. ECS J. Solid State Sci. Technol., 2017, 6, P. 687-690.

[34] Suda S. Nanocomposite glass abrasives. Journal of the Ceramic Society of Japan, 2014, 122, P. $244-249$. 